\title{
The relation of metabolic syndrome according to five definitions to cardiovascular risk factors - a population-based study
} Cheng-Chieh Lin ${ }^{1,2,3,4,5}$, Chiu-Shong Liu ${ }^{1,2,3}$, Chia-Ing Li ${ }^{3}$, Wen-Yuan Lin ${ }^{1,2}$, Ming-May Lai1,2, Tsann Lin 1,2,3, Pei-Chia Chang6, Yih-Dar Lee ${ }^{7}$, Ching-Chu Chen ${ }^{8}$, Chih-Hsueh Lin ${ }^{1,2}$, Chuan-Wei Yang ${ }^{3}$, Chih-Yi Hsiao ${ }^{9}$, Walter Chen ${ }^{10}$ and Tsai-Chung $\mathrm{Li}^{* 11,12}$

Address: ${ }^{1}$ Department of Family Medicine, China Medical University Hospital, Taichung, Taiwan, ${ }^{2}$ Department of Family Medicine, College of Medicine, China Medical University, Taichung, Taiwan, ${ }^{3}$ Medical Research, China Medical University Hospital, Taichung, Taiwan, ${ }^{4}$ Institute of Health Care Administration, College of Health Science, Asia University, Taichung, Taiwan, ${ }^{5}$ School and Graduate Institute of Health Care Administration, College of Public Health, China Medical University, Taichung, Taiwan, ${ }^{6}$ Administration Center, China Medical University Hospital, Taichung, Taiwan, ${ }^{7}$ Lilly Taiwan, Eli Lilly and Company, Taipei, Taiwan, ${ }^{8}$ Division of Endocrinology and Metabolism, Department of Medicine, China Medical University Hospital, Taichung, Taiwan, 'Institute of Health Care Administration, College of Public Health, China Medical University, Taichung, Taiwan, ${ }^{10}$ Department of Medicine, China Medical University, Taichung, Taiwan, ${ }^{11}$ Institute of Biostatistics, China Medical University, Taichung, Taiwan and 12Biostatistics Center, China Medical University, Taichung, Taiwan

Email: Cheng-Chieh Lin - cclin@mail.cmuh.org.tw; Chiu-Shong Liu - liucs@ms14.hinet.net; Chia-Ing Li - a6446@mail.cmuh.org.tw; WenYuan Lin - wylin@mail.cmu.edu.tw; Ming-May Lai - mmlai@ms26.hinet.net; Tsann Lin - tsann.lin@msa.hinet.net; Pei-

Chia Chang - lisa319.tw@yahoo.com.tw; Yih-Dar Lee - tphillee.tw@yahoo.com.tw; Ching-Chu Chen - chingchu@ms15.hinet.net; ChihHsueh Lin - lys0922lin2005@yahoo.com.tw; Chuan-Wei Yang -T14636@mail.cmuh.org.tw; Chih-Yi Hsiao - hsiao.joy@gmail.com; Walter Chen - chenwalt@mail.cmu.edu.tw; Tsai-Chung Li* - tcli@mail.cmu.edu.tw

* Corresponding author

Published: 23 December 2009

BMC Public Health 2009, 9:484 doi:10.1 186/147/-2458-9-484
Received: 8 April 2009

Accepted: 23 December 2009

This article is available from: http://www.biomedcentral.com/I47I-2458/9/484

(C) 2009 Lin et al; licensee BioMed Central Ltd.

This is an Open Access article distributed under the terms of the Creative Commons Attribution License (http://creativecommons.org/licenses/by/2.0), which permits unrestricted use, distribution, and reproduction in any medium, provided the original work is properly cited.

\begin{abstract}
Background: Although National Cholesterol Education Program (NCEP), International Diabetes Federation (IDF), American Heart Association and National Heart, Lung and Blood Institute (AHA/ NHLBI), World Health Organization (WHO), and the European Group for the Study of Insulin Resistance (EGIR) definitions of metabolic syndrome (MetS) have been commonly used by studies, little is known about agreement among these five definitions. We examined the agreement among these five definitions and explored their relationship with risk factors of cardiovascular disease in a Taiwan population.
\end{abstract}

Methods: A total of 1305 subjects aged 40 years and over in Taiwan were analyzed. Biomedical markers and anthropometric indices were measured. Agreement among definitions was determined by the kappa statistic. Logistic regression models were fit to estimate the odds of a high cardiovascular risk group for five definitions of MetS.

Results: The agreement among the NCEP, IDF, and AHA/NHLBI definitions was from substantial to very good, and agreement between the WHO and EGIR definitions was also substantial. All MetS definitions were significantly associated prevalence of microalbuminuria, elevated highly sensitive CRP (hs-CRP), and arterial stiffness only in women. In men, MetS by NCEP and AHA/NHLBI was associated with elevated level of hs-CRP and arterial stiffness. MetS by WHO and EGIR were 
significantly associated with microalbuminuria. And MetS by WHO was the only MetS definition that significantly associated with prevalence of arterial stiffness (OR: 2.75, 95\% Cl: 1.22-6.19).

Conclusions: The associations of these five definitions with cardiovascular risk factors were similar in women, and it was evident that the five definitions performed better in women than in men, with higher ORs observed in relation to arterial stiffness, elevated hs-CRP, and higher Framingham risk scores.

\section{Background}

Metabolic syndrome (MetS) has been shown to increase the risk of CVD mortality and all-cause mortality [1-3]. World Health Organization (WHO) [4] was the first to propose criteria for the diagnosis of MetS, followed by European Group for the Study of Insulin Resistance (EGIR) [5]. In WHO and EGIR definitions, the presence of insulin resistance was a prerequisite. National Cholesterol Education Program (NCEP) Adult Treatment Panel III (ATP-III) assigned MetS as a secondary target for intervention [6]. In 2005, the International Diabetes Federation (IDF) presented a MetS definition [7], in which central obesity was the prerequisite and different cut-off values for waist circumference were introduced for different ethnic groups. The American Heart Association and the National Heart, Lung and Blood Institute (AHA/NHLBI) modified the NCEP criteria by decreasing the glucose cutoff from 110 to $100 \mathrm{mg} / \mathrm{dl}$ [8]. Although these definitions have been commonly used by studies, little is known about agreement among these five definitions of MetS, especially the data in the AHA/NHLBI definition.

The value of MetS in health care contexts derives in large part from its potential to reduce the risk of CVD by treating the disease. One way to understand which MetS definitions are more useful in practice is to examine the relationships between these MetS definitions and CVD risk factors. Some factors have been shown to be associated with an increased risk of CVD. Microalbuminuria is one of the strongest predictors of glomerular filtration rate decline, and it is associated with a higher risk of cardiovascular disease and mortality $[4,9]$. Several cross-sectional studies for Asians had been conducted to examine the relationship of metabolic syndrome with microalbuminuria in senior citizens of rural Japanese [10], in diabetic Japanese patients [11], in urban Chinese residents aged 40 years and over [12], in a Korean adults seeking health check-up [13]. Arterial stiffness and peripheral vascular disease (PVD) are two major underlying pathophysiologies of arterial disease and they are the primary cause of CVD [14]. The effect of MetS defined by NECP, IDF, or AHA/NHLBI criteria on arterial stiffness have been examined in Japanese [15-18], in Korean [19], and in Chinese [20] by cross-sectional studies. Highly sensitive C-reactive protein (hs-CRP) is a marker of systemic inflammation in the body. Mild chronic elevations of hs-CRP concentrations are independently predictive of future cardiovascular events $[21,22]$. The association of hs-CRP with MetS has been explored in a study of 179 middle-aged Chinese men with a family history of diabetes from a university teaching hospital [23]. The Framingham Risk Scoring System is an index of the 10-year risk of fatal and nonfatal CVD. The effect of the diagnosis of MetS using NECP, WHO and IDF criteria on Framingham risk score have been examined in Korean subjects who seek for physical check-up [24]. The present study seeks to extend existing research by examining the relationship between various MetS definitions and these cardiovascular risk factors simultaneously.

We posed two questions in the present research: what is the estimate of agreement among the various MetS definitions? Which MetS definitions are associated with the risk factors for CVD.

\section{Methods}

\section{Study population}

This was a cross-sectional epidemiological study based on data from the Taichung Community Health Study. A total of 2,359 residents aged 40 and over in Taichung City, Taiwan, participated in October 2004. A two-stage sampling design was used, with a sampling rate proportional to size within each stage. At each stage, simple random sampling was used. In the first stage of sampling, the sampling unit was Li (administrative units) and the selection probability for Li was set at 0.125 . A total of 39 Lis were randomly selected from 8 city districts. In the second stage, 110 individuals were randomly selected from each sample Li. A total of 4280 individuals were selected and 750 individuals who were not eligible were excluded. A total of 3,530 subjects were eligible, and 2,359 agreed to participate with an overall response rate of $66.83 \%$. The detailed methodology has been described elsewhere $[12,20,25,26]$.

Insulin levels only were measured in the first 1305 subjects and they were analyzed in the current analysis. This study was approved by the Human Research Committee of China Medical University Hospital. Written informed consent was obtained from each participant. 


\section{Data collection}

Anthropometric measurements were obtained from the complete physical examination. Weight and height were measured on an autoanthropometer (super-view, HW666), with subjects shoeless and wearing light clothing. Body mass index (BMI) was derived from the formula of weight $(\mathrm{kg}) \div$ (height $)^{2}\left(\mathrm{~m}^{2}\right)$. With the participant standing, waist circumference was measured midway between the superior iliac crest and the costal margin. Percent body fat mass (\%FM) was assessed by conventional tetrapolar bioelectrical impedance analysis using the Tanita BC-418 MA Impedanciometer (Tanita Corp., Tokyo, Japan) [27]. Blood pressure was measured using an electronic device (COLIN, VP-1000, Japan).

The measurement of brachial-ankle pulse wave velocity (baPWV) and the ankle-brachial index (ABI) were determined using an automatic waveform analyzer (VP-1000; Colin Co., Komaki, Japan) with well-documented validity and reproducibility (coefficient of variation $[\mathrm{CV}]=3.31 \%$ and reproducibility coefficient $=0.947$ ). Higher baPWV values indicated more severe arterial stiffness. Lower ABI values indicated more severe PVD. High baPWV was defined as a value higher than $1,400 \mathrm{~cm} / \mathrm{s}$, whereas an ABI index $<0.9$ was considered the presence of PVD [28].

Blood was drawn with minimal trauma from an antecubital vein in the morning, after a 12-hour overnight fasting, and was sent for analysis within four hours of collection. Biochemical markers such as fasting plasma glucose, high-density lipoprotein cholesterol (HDL-C), triglyceride, urine albumin and creatinine were analyzed by a biochemical autoanalyzer (Beckman Coluter Synchron system, Lx-20, Fullerton, CA, USA) at the Clinical Laboratory Department of China Medical University Hospital. Plasma cholesterol and triglyceride levels were determined by an enzymatic colorimetric method. The HDL-C level was measured by a direct HDL-C method and the low-density lipoprotein cholesterol (LDL-C) level was measured by a direct LDL-C method, too. The serum insulin level was measured by a commercial enzyme-linked immunosorbent assay kit (Diagnostic Products, Los Angeles, CA). The interassay CV for insulin was $8.7 \%$ and the intra-assay CV was $3.4 \%$. Insulin sensitivity was estimated with a Homeostasis Model Assessment (HOMA-IR) equation. The HOMA-IR equals fasting serum insulin $(\mu \mathrm{U} / \mathrm{ml})$ times fasting plasma glucose $(\mathrm{mmol} / \mathrm{l})$ divided by 22.5 [29]. Hs-CRP levels were measured by nephelometry, a latex particle-enhanced immunoassay (TBA-200FR, Tokyo, Japan). The interassay and intraassay CVs were $<2.0 \%$ and $<1.9 \%$, respectively. The lower detection limit of the assay was $0.1 \mathrm{mg} / \mathrm{L}$. The urinary albumin-to-creatinine ratio (ACR) in the morning urine sample was used as a marker of the albumin excretion rate. Urinary creatinine (Jaffe's kinetic method) and albumin (colorimetyl brom- cresol purple) were measured by an autoanalyzer. The interassay precision coefficient of variation was $<3.0 \%$ for both creatinine and albumin concentrations. Urinary ACR ranging from $30 \mathrm{mg}$ g- 1 creatinine to $300 \mathrm{mg}$ g- 1 creatinine was defined as microalbuminuria [30].

Using the Framingham risk score based on the LDL-C level [31], the estimated total coronary heart disease risk over a 10-year period for every individual was calculated. Data on sociodemographic characteristics, including gender, age, smoking, drinking, physical activity, occupational activity, menopausal status, family history of cardiovascular-related diseases, physician-diagnosed diseases, and medication history were collected when the participants underwent a complete physical examination.

\section{The metabolic syndrome}

Table 1 shows the criteria of the five MetS definitions studied. An Asian modification of the NCEP ATP-III definition of MetS was used [32]. For WHO definition, we used HOMA-IR to define insulin resistance. A similar modification was used in previous studies $[33,34]$. We defined the subjects in the highest quartile of the HOMA-IR distribution as insulin resistant [5]. The cutoff value of HOMA-IR for non-diabetic subjects was 2.53 in this study and the corresponding cutoff value of EGIR defined insulin resistance was $10.40 \mu \mathrm{U} / \mathrm{ml}$ or $74.6 \mathrm{pmol} / \mathrm{L}$. For medications, they have to be prescribed by their physicians. For hypertension, there are 4 types of treatment: angiotension II converting enzyme inhibitor (ACEI), angiotensis II receptor blocker, calcium channel blocker, and diuretics. For low HDL and raised triglycerides, there are 4 types of treatment: statins, bile acid sequestrants, nicotinic acid, and fibric acids.

\section{Statistical analysis}

Continuous variables were reported as mean \pm standard deviation (SD) and categorical variables were reported as percentages. Agreement between the five definitions of MetS was determined using the kappa statistic $(\kappa)$. The level of agreement was considered poor with 0.20 , fair with $\kappa=0.21-0.40$, moderate with $\kappa=0.41-0.60$, substantial with $\kappa=0.61-0.80$, and very good with $\kappa>0.80$ [35]. Logistic regression models were fit to estimate the odds of high cardiovascular risk group for five definitions of MetS. The high risk groups for \%FM, hs-CRP, and Framingham risk scores were determined by the upper quartile of their distribution. All reported p values were those of two-sided tests; statistical significance was set at $\mathrm{p}<0.05$. All analyses were performed using SAS version 9.1 (SAS Institute Inc, Cary, NC).

\section{Results}

The distributions of sociodemographic, anthropometric and biochemical characteristics and prevalence of meta- 
Table I: Definitions of metabolic syndrome according to the NCEP ATP III, IDF, AHA, WHO, and EGIR criteria

\begin{tabular}{|c|c|c|c|c|c|}
\hline & \multicolumn{5}{|c|}{ Definition of Metabolic Syndrome (MetS) } \\
\hline & NCEP & IDF & AHA & WHO & EGIR \\
\hline Definition of MetS & $\begin{array}{l}\text { Any } 3 \text { of } 5 \text { criteria } \\
\text { listed below }\end{array}$ & $\begin{array}{l}\text { Increased waist plus } \\
\text { any of } 2 \text { of other } 4 \\
\text { criteria }\end{array}$ & $\begin{array}{l}\text { Any } 3 \text { of } 5 \text { criteria } \\
\text { listed below }\end{array}$ & $\begin{array}{l}\text { IFG, IGT, or IR plus } 2 \\
\text { of other } 5 \text { criteria }\end{array}$ & $\begin{array}{l}\text { Insulin in top } 25 \% \text { plus } \\
2 \text { of other } 4 \text { criteria }\end{array}$ \\
\hline BMI $\left(\mathrm{kg} / \mathrm{m}^{2}\right)$ & -- & -- & -- & $>30$ & -- \\
\hline $\begin{array}{l}\text { Abdominal obesity } \\
\text { (men/women) }\end{array}$ & Waist $>90 / 80$ & Waist $\geqq 90 / 80$ & Waist $\geqq 90 / 80$ & $\begin{array}{l}\text { Waist-to-hip ratio } \\
>0.9 / 0.85\end{array}$ & Waist $\geqq 94 / 80$ \\
\hline Triglycerides (nmol/L) & $\begin{array}{l}\geqq 1.7 \text { or drug } \\
\text { treatment for this lipid } \\
\text { abnormality }\end{array}$ & $\begin{array}{l}\geqq 1.7 \text { or drug } \\
\text { treatment for this lipid } \\
\text { abnormality }\end{array}$ & $\begin{array}{l}\geqq 1.7 \text { or drug } \\
\text { treatment for this lipid } \\
\text { abnormality }\end{array}$ & $\begin{array}{l}\geqq 1.7 \text { or drug } \\
\text { treatment for this lipid } \\
\text { abnormality }\end{array}$ & $\begin{array}{l}>2.0 \text { or drug } \\
\text { treatment for this lipid } \\
\text { abnormality }\end{array}$ \\
\hline $\begin{array}{l}\text { HDL cholesterol } \\
\text { (nmol/L) (men/ } \\
\text { women) }\end{array}$ & $\begin{array}{l}<1.0 / 1.3 \text { or drug } \\
\text { treatment for this lipid } \\
\text { abnormality }\end{array}$ & $\begin{array}{l}<1.0 / 1.3 \text { or drug } \\
\text { treatment for this lipid } \\
\text { abnormality }\end{array}$ & $\begin{array}{l}<1.0 / 1.3 \text { or drug } \\
\text { treatment for this lipid } \\
\text { abnormality }\end{array}$ & $\begin{array}{l}<0.9 / 1.0 \text { or drug } \\
\text { treatment for this lipid } \\
\text { abnormality }\end{array}$ & $\begin{array}{l}<1.0 \text { or drug } \\
\text { treatment for this lipid } \\
\text { abnormality }\end{array}$ \\
\hline $\begin{array}{l}\text { Blood pressure } \\
(\mathrm{mmHg})\end{array}$ & $\begin{array}{l}\geqq 130 / \geqq 85 \text { or drug } \\
\text { treatment for } \\
\text { hypertension }\end{array}$ & $\begin{array}{l}\geqq 130 / \geqq 85 \text { or drug } \\
\text { treatment for } \\
\text { hypertension }\end{array}$ & $\begin{array}{l}\geqq 130 / \geqq 85 \text { or drug } \\
\text { treatment for } \\
\text { hypertension }\end{array}$ & $\begin{array}{l}\geqq 140 / \geqq 90 \text { or drug } \\
\text { treatment for } \\
\text { hypertension }\end{array}$ & $\begin{array}{l}\geqq \mid 40 / \geqq 90 \text { or drug } \\
\text { treatment for } \\
\text { hypertension }\end{array}$ \\
\hline HOMA-IR & -- & -- & -- & $>2.53$ & -- \\
\hline $\begin{array}{l}\text { Fasting glucose } \\
(\mathrm{nmol} / \mathrm{L})\end{array}$ & $\geqq 6.1$ & $\geqq 5.6$ & $\geqq 5.6$ & $\geqq 6.1$ & $\geqq 6.1$ \\
\hline $\begin{array}{l}\text { Fasting insulin } \\
(\mathrm{pmol} / \mathrm{L})\end{array}$ & -- & -- & -- & -- & $>74.6$ (Top 25\%) \\
\hline $\begin{array}{l}\text { Urinary albumin } \\
\text { excretion }\end{array}$ & -- & -- & -- & $\geqq 30 \mathrm{mg} / \mathrm{g}$ creatinine & -- \\
\hline
\end{tabular}

National Cholesterol Education Program (NCEP) Adult Treatment Panel III (ATP-III), International Diabetes Federation (IDF), American Heart Association and National Heart Lung and Blood Institute (AHA/NHLBI), World Health Organization (WHO), European Group for the Study of Insulin Resistance (EGIR), metabolic syndrome (MetS), body mass index (BMI), high-density lipoprotein (HDL), homeostasis model assessment of insulin resistance (HOMA-IR), insulin resistance (IR).

bolic syndrome according to 5 definitions for all study subjects, and according to gender are summarized in Table 2. Agreement among the five definitions of MetS is shown in Table 3. Agreement among the NCEP ATP-III, IDF, and AHA/NHLBI definitions was from substantial to very good ( $\kappa$ : $0.63-0.84$ for men and $0.68-0.85$ for women), and that between the WHO and EGIR definitions was also substantial ( $\kappa$ : 0.64 for men and 0.65 for women). Agreement between NCEP ATP-III, IDF or AHA/ NHLBI and WHO or EGIR definitions was from fair to moderate for both men and women.

The adjusted odds ratios (ORs) of the high risk group for cardiovascular risk factors according to each definition of MetS are shown in Table 4. All MetS definitions were significantly associated with prevalence of high \%FM and high Framingham risk scores in both men and women. In men, MetS by NCEP, AHA and WHO were associated with an increase prevalence of arterial stiffness and hs-CRP. In addition, MetS by NCEP, AHA, WHO and EGIR were significantly associated with microalbuminuria, and MetS by the WHO was the only MetS definition that significantly associated with PVD. In women, all MetS definitions were significantly associated with a prevalence of microalbuminuria, arterial stiffness, higher \% FM, and elevated hsCRP, except for the EGIR with microalbuminuria. In men, MetS of all definitions had larger ORs with high \%FM than with the other CVD risk factors, while in women, MetS had larger ORs with high \%FM and Framingham risk scores than with the other CVD risk factors.

In additional file 1 Table S1 shows the relationships between cardiovascular risk factors and components of metabolic syndrome according to five definitions. In men, most of components were associated with significant adjusted OR in a similar way with the exception of obesity component of WHO with arterial stiffness, obesity component of EGIR with elevated hs-CRP, raised TG component of NCEP/IDF/AHA/WHO with elevated hs-CRP, raised blood pressure of NCEP/IDF/AHA with PVD, raised fasting glucose of IDF/AHA and WHO with elevated hsCRP. In women, most of components were also associated with significant adjusted OR in a similar way with the exception of obesity component of NCEP, IDF/AHA/EGIR with arterial stiffness, raised TG component of EGIR with PVD and higher \%FM, low HDL-cholesterol of NCEP/ IDF/AHA with arterial stiffness and higher \%FM, raised fasting glucose of NCEP/EGIR and WHO with higher $\%$ FM and elevated hs-CRP.

\section{Discussion}

Our data show the kappa agreement between the definitions not considering insulin measurement (NCEP, AHA/ NHLBI, or IDF) and the definitions requiring insulin 
Table 2: Distributions of sociodemographic, anthropometric and biochemical characteristics, and prevalence of metabolic syndrome according to 5 definitions for all study subjects, and according to gender

\begin{tabular}{|c|c|c|c|}
\hline & \multicolumn{3}{|c|}{ Mean (SD) } \\
\hline & $\begin{array}{l}\text { Overall } \\
(N=1305)\end{array}$ & $\begin{array}{l}\text { Men } \\
(N=633)\end{array}$ & $\begin{array}{l}\text { Women } \\
(N=672)\end{array}$ \\
\hline Age (years) & $55.99(11.25)$ & $57.71(12.23)$ & $54.37(9.98)$ \\
\hline Smoking $(\%)^{\dagger}$ & $198(15.18)$ & $175(27.65)$ & $23(3.43)$ \\
\hline Drinking $(\%)^{\dagger}$ & $314(24.08)$ & $242(38.23)$ & $72(10.73)$ \\
\hline Betel nut chewing $(\%)^{\dagger}$ & $40(3.07)$ & $39(6.18)$ & $\mathrm{I}(0.15)$ \\
\hline Exercise $(\%)^{\text {ta }}$ & $865(66.33)$ & $423(66.93)$ & $442(65.77)$ \\
\hline Body mass index $\left(\mathrm{kg} / \mathrm{m}^{2}\right)$ & $24.35(3.26)$ & $24.87(3.11)$ & $23.85(3.33)$ \\
\hline Waist circumference $(\mathrm{cm})$ & 81.71 (9.87) & $86.74(8.55)$ & $76.98(3.61)$ \\
\hline Waist-to-hip ratio & $0.85(0.07)$ & $0.89(0.05)$ & $0.81(0.06)$ \\
\hline Fasting blood glucose $(\mathrm{mmol} / \mathrm{l})$ & $5.74(1.53)$ & $5.87(1.53)$ & $5.61(1.53)$ \\
\hline Fasting insulin (pmol/l) & $60.92(48.50)$ & $64.65(48.38)$ & $57.40(48.43)$ \\
\hline HOMA-IR & $2.06(2.23)$ & $2.43(2.13)$ & $2.11(2.30)$ \\
\hline Triglyceride (mmol/l) & $1.32(0.99)$ & $1.49(1.16)$ & $1.16(0.76)$ \\
\hline HDL-cholesterol (mmol/l) & $1.20(0.34)$ & $1.07(0.28)$ & I.3I (0.34) \\
\hline LDL-cholesterol (mmol/l) & $3.34(0.88)$ & $3.37(0.87)$ & $3.32(0.89)$ \\
\hline Diastolic blood glucose $(\mathrm{mmHg})$ & $78.37(11.94)$ & $81.77(10.82)$ & $75.14(12.05)$ \\
\hline Systolic blood glucose $(\mathrm{mmHg})$ & $133.68(20.68)$ & $|36.5|(19.53)$ & $131.02(21.38)$ \\
\hline Hypertension (\%) ${ }^{\dagger}$ & $354(27.21)$ & $189(29.91)$ & $165(24.66)$ \\
\hline Family history of diabetes $(\%)^{\dagger}$ & $330(25.10)$ & $157(24.84)$ & $173(25.74)$ \\
\hline Microalbuminuria $(\% / A C R \geqq 30 \mu \mathrm{g} / \mathrm{min})^{\dagger}$ & $278(21.38)$ & $120(18.99)$ & $158(23.65)$ \\
\hline PVDtb & $86(6.59)$ & $37(5.85)$ & $49(7.29)$ \\
\hline Arterial stiffness $t c$ & $838(64.76)$ & $455(72.45)$ & $383(57.5 \mathrm{I})$ \\
\hline$\% F M$ & $31.59(7.62)$ & $26.45(5.50)$ & $36.40(6.02)$ \\
\hline $\mathrm{Hs}-\mathrm{CRP}(\mathrm{mg} / \mathrm{L})$ & $0.25(0.50)$ & $0.26(0.54)$ & $0.23(0.46)$ \\
\hline Metabolic syndrome by NCEP ATP-III & $410(31.42)$ & $226(35.70)$ & $184(27.38)$ \\
\hline Metabolic syndrome by IDF & $328(25.13)$ & $167(26.38)$ & $161(23.96)$ \\
\hline Metabolic syndrome by AHA & $501(38.39)$ & $275(43.44)$ & $226(33.63)$ \\
\hline Metabolic syndrome by WHO & $246(18.85)$ & $154(24.33)$ & $92(13.69)$ \\
\hline Metabolic syndrome by EGIR* & $203(15.56)$ & $123(19.43)$ & $80(11.90)$ \\
\hline
\end{tabular}

homeostasis model assessment of insulin resistance (HOMA-IR), high-density lipoprotein (HDL), low-density lipoprotein (LDL), albumin-creatinine ratio $(A C R)$, ankle-brachial index $(\mathrm{ABI})$, brachial-ankle pulse wave velocity (baPWV), percent body fat mass (\%FM), peripheral vascular disease (PVD), highly sensitive C-reactive protein (hs-CRP), National Cholesterol Education Program (NCEP) Adult Treatment Panel III (ATP-III), International Diabetes Federation (IDF), American Heart Association and National Heart Lung and Blood Institute (AHA/NHLBI), World Health Organization (WHO), European Group for the Study of Insulin Resistance (EGIR). t: n (\%). *:A total of I 305 samples, includes 633 men and 672 women. a: Participants reported they spent at least 20 minutes in any types of recreational activity at least 3 times per week for more than 6 months. b: peripheral vascular disease $(\mathrm{PVD})$ : ankle-brachial index $(\mathrm{ABI})<0.9$. c: arterial stiffness: brachial-ankle pulse wave velocity $($ baPWV) $>$ $1400 \mathrm{~cm} / \mathrm{s}$.

measurement (WHO or EGIR) ranged from 0.33 to 0.46 in men and from 0.34 to 0.42 in women, and was from fair to moderate, similar to previous findings [34,36]. AHA/NHLBI was not evaluated in Can's and Dekker's work and IDF was not evaluated in Dekker's work. But the agreement between IDF and WHO definitions in our study $(\kappa=0.37)$ was much lower than in GuerreroRomero's work $(\kappa=0.51)$ [37]. We found a substantial agreement $(\kappa=0.67)$ between NCEP and IDF definitions, much lower than those in Can's and Guerrero-Romero's studies (both $\kappa=0.87$ ), but higher than that $(\kappa=0.54)$ in the Korean Health and Examination Survey [38].

Our study identified similarities among the five definitions of MetS, but also revealed differences. In men, all definitions were associated with high \%FM and high Framingham risk scores. The only definitions associated with microalbuminuria were those considering insulin resistance (WHO and EGIR criteria), and WHO definition was the only predictor of PVD. On the other hand, the NCEP ATP III and AHA definitions, which did not consider insulin resistance, were associated with arterial stiffness and elevated hs-CRP. IDF definition was not correlated with arterial stiffness or elevated hs-CRP, possibly due to its prerequisite factor. In general, the associations of these five definitions with cardiovascular risk factors were similar in women, and it was evident that the five definitions in women performed better than in men, with higher ORs observed in relation to arterial stiffness, 
Table 3: Agreement between each definition of the metabolic syndrome. ${ }^{a}$

\begin{tabular}{lcccc}
\hline & NCEP & IDF & AHA & WHO \\
\hline Men & & & & \\
IDF & $0.63(0.57-0.70)$ & $0.64(0.58-0.69)$ & $0.43(0.36-0.49)$ & $0.64(0.56-0.71)$ \\
AHA & $0.84(0.80-0.88)$ & $0.40(0.32-0.48)$ & $0.37(0.31-0.44)$ & \\
WHO & $0.49(0.42-0.56)$ & $0.47(0.39-0.55)$ & & \\
EGIR & $0.44(0.37-0.52)$ & & & $0.43(0.36-0.50)$ \\
Women & $0.68(0.62-0.75)$ & $0.77(0.71-0.82)$ & $0.37(0.30-0.43)$ & $0.65(0.57-0.74)$ \\
IDF & $0.85(0.81-0.90)$ & $0.43(0.35-0.51)$ & $0.40(0.32-0.49)$ & \\
AHA & $0.49(0.42-0.57)$ & $0.40(0.32-0.48)$ & & \\
WHO & & & & \\
EGIR & &
\end{tabular}

a: kappa statistics and their $95 \%$ confidence interval were presented.

National Cholesterol Education Program (NCEP) Adult Treatment Panel III (ATP-III), International Diabetes Federation (IDF), American Heart Association and National Heart Lung and Blood Institute (AHA/NHLBI), World Health Organization (WHO), European Group for the Study of Insulin Resistance (EGIR).

elevated hs-CRP, and higher Framingham risk scores, and more ORs significantly related to microalbuminuria.

The reason why IDF definition correlated less well with arterial stiffness or elevated hs-CRP, compared to NCEP ATP III or AHA/NHLBI definition, may be that central obesity is a prerequisite factor of IDF definition. Central obesity is believed to be associated with insulin resistance and has been suggested to induce insulin resistance and hyperinsulinemia, owing to the influence of free fatty acids, derived from visceral fat, on the liver [39]. Khoo et al. [40] determined the effect of the presence of central obesity on insulin resistance and other cardiovascular risk factors. They found that central obesity is important for the identification of individuals with insulin resistance and glucose intolerance; whereas AHA/NHLBI definition is more appropriate in identifying those at increased risk of cardiovascular disease. A significant proportion of individuals in their population (ranging from $10 \%$ to $13 \%$ in men and $2 \%$ to $4 \%$ in women) exhibited multiple features of MetS in the absence of central obesity. In our study, this proportion was even higher $(14.75 \%$ in men

Table 4: The adjusted OR for metabolic syndrome of each studied definition associated with cardiovascular risk factors

\begin{tabular}{|c|c|c|c|c|c|c|c|c|c|c|}
\hline & \multicolumn{10}{|c|}{ Adjusted OR $(95 \% \mathrm{CI})^{\mathrm{a}}$} \\
\hline & \multicolumn{5}{|c|}{$\operatorname{Men}(N=633)$} & \multicolumn{5}{|c|}{ Women $(\mathbf{N}=672)$} \\
\hline & NCEP & IDF & AHA & WHO & EGIR & NCEP & IDF & AHA & WHO & EGIR \\
\hline $\begin{array}{l}\text { Microalbu } \\
\text { minuria }\end{array}$ & $\begin{array}{c}1.99 * * \\
(1.31-3.03)\end{array}$ & $\begin{array}{c}|.5| \\
(0.97-2.35)\end{array}$ & $\begin{array}{c}1.64^{*} \\
(1.08-2.50)\end{array}$ & $\begin{array}{c}4.44^{* * *} \\
(2.85-6.91)\end{array}$ & $\begin{array}{c}2.62 * * * \\
(1.49-4.60)\end{array}$ & $\begin{array}{c}2.21^{* * *} \\
(1.47-3.32)\end{array}$ & $\begin{array}{c}2.29 * * * \\
(1.51-3.48)\end{array}$ & $\begin{array}{c}2.26 * * * \\
(1.52-3.38)\end{array}$ & $\begin{array}{c}4.16 * * * \\
(2.57-6.73)\end{array}$ & $\begin{array}{c}1.80 \\
(0.99-3.29)\end{array}$ \\
\hline PVD & $\begin{array}{c}1.29 \\
(0.65-2.59)\end{array}$ & $\begin{array}{c}1.48 \\
(0.72-3.20)\end{array}$ & $\begin{array}{c}1.36 \\
(0.69-2.70)\end{array}$ & $\begin{array}{c}2.24^{*} \\
(\mathrm{I} . \mathrm{I} \mid-4.55)\end{array}$ & $\begin{array}{c}2.17 \\
(0.92-5.10)\end{array}$ & $\begin{array}{c}1.68 \\
(0.83-3.40)\end{array}$ & $\begin{array}{c}1.20 \\
(0.57-2.54)\end{array}$ & $\begin{array}{c}1.17 \\
(0.58-2.33)\end{array}$ & $\begin{array}{c}1.34 \\
(0.56-3.19)\end{array}$ & $\begin{array}{c}1.12 \\
(0.38-3.33)\end{array}$ \\
\hline $\begin{array}{l}\text { Arterial } \\
\text { stiffness }\end{array}$ & $\begin{array}{c}3.07 * * * \\
(1.92-4.92)\end{array}$ & $\begin{array}{c}1.27 \\
(0.79-2.03)\end{array}$ & $\begin{array}{c}2.90 * * * \\
(1.88-4.48)\end{array}$ & $\begin{array}{c}1.95 * \\
(1.15-3.29)\end{array}$ & $\begin{array}{c}1.40 \\
(0.80-2.47)\end{array}$ & $\begin{array}{c}3.72 * * * \\
(2.23-6.20)\end{array}$ & $\begin{array}{c}3.18 * * * \\
(1.88-5.40)\end{array}$ & $\begin{array}{c}3.99 * * * \\
(2.50-6.35)\end{array}$ & $\begin{array}{l}6.61 * * * \\
(2.93- \\
14.92)\end{array}$ & $\begin{array}{l}4.63 * * \\
(2.02- \\
10.63)\end{array}$ \\
\hline $\begin{array}{l}\text { Higher } \\
\text { \%FM }\end{array}$ & $\begin{array}{l}6.93 * * * \\
(4.66- \\
10.28)\end{array}$ & $\begin{array}{l}\text { I I.29*** } \\
(7.39- \\
\text { I7.23) }\end{array}$ & $\begin{array}{c}5.55^{* * * *} \\
(3.73-8.26)\end{array}$ & $\begin{array}{c}5.58 * * * \\
(3.72-8.37)\end{array}$ & $\begin{array}{l}10.76 * * * \\
(6.35- \\
18.23)\end{array}$ & $\begin{array}{c}4.56 * * * \\
(3.05-6.82)\end{array}$ & $\begin{array}{c}8.88 * * * \\
(5.78- \\
13.65)\end{array}$ & $\begin{array}{c}4.31^{* * * *} \\
(2.90-6.42)\end{array}$ & $\begin{array}{c}3.24 * * * \\
(2.01-5.23)\end{array}$ & $\begin{array}{l}8.30 * * * \\
(4.47- \\
15.41)\end{array}$ \\
\hline $\begin{array}{l}\text { Elevated } \\
\text { hs-CRP }\end{array}$ & $\begin{array}{c}1.78 * * \\
(1.23-2.59)\end{array}$ & $\begin{array}{c}1.15 \\
(0.77-1.73)\end{array}$ & $\begin{array}{c}1.71 * * \\
(1.19-2.48)\end{array}$ & $\begin{array}{c}1.66^{*} \\
(1.11-2.50)\end{array}$ & $\begin{array}{c}1.45 \\
(0.87-2.42)\end{array}$ & $\begin{array}{c}3.09 * * * \\
(2.07-4.62)\end{array}$ & $\begin{array}{c}2.25 * * \\
(1.49-3.39)\end{array}$ & $\begin{array}{c}2.63^{* * *} \\
(1.78-3.89)\end{array}$ & $\begin{array}{c}4.42 * * * \\
(2.73-7.15)\end{array}$ & $\begin{array}{c}4.14^{* * *} \\
(2.28-7.52)\end{array}$ \\
\hline $\begin{array}{l}\text { Higher risk } \\
\text { scores }^{b}\end{array}$ & $\begin{array}{c}4.13 * * * \\
(2.62-6.51)\end{array}$ & $\begin{array}{c}2.60 * * * \\
(1.64-4.13)\end{array}$ & $\begin{array}{c}3.82 * * * \\
(2.44-5.98)\end{array}$ & $\begin{array}{c}4.65 * * * \\
(2.84-7.62)\end{array}$ & $\begin{array}{c}2.79 * * * \\
(1.48-5.26)\end{array}$ & $\begin{array}{l}9.51 * * * \\
(5.94- \\
15.21)\end{array}$ & $\begin{array}{c}4.77 * * * \\
(3.00-7.59)\end{array}$ & $\begin{array}{l}10.25^{* * *} \\
(6.54- \\
16.07)\end{array}$ & $\begin{array}{l}10.57^{* * *} \\
(5.48- \\
20.42)\end{array}$ & $\begin{array}{l}5.54 * * * \\
(2.73- \\
\text { I I.27) }\end{array}$ \\
\hline
\end{tabular}

aLogistic regression adjusted for age, smoking, alcohol drinking, betel nut chewing, low income, education.

bFramingham risk score ${ }^{31}$; microalbuminuria: albumin-creatinine ratio (ACR) $>30 \mathrm{mg}$ g-I creatinine, peripheral vascular disease (PVD): anklebrachial index $(\mathrm{ABI})<0.9$; arterial stiffness: brachial-ankle pulse wave velocity (baPWV) $>$ I $400 \mathrm{~cm} / \mathrm{s}$; higher percent body fat mass (\%FM) greater than the cutoff value of $3^{\text {th }}$ quartile; elevated highly sensitive C-reactive protein (hs-CRP): greater than the cutoff value of $3^{\text {th }}$ quartile; higher risk scores: Framingham risk score greater than the cutoff value of $3^{\text {th }}$ quartile.

*: $\mathrm{p}<0.05 ; * *: \mathrm{p}<0.01$; ***: $\mathrm{p}<0.001$ 
and $7.99 \%$ in women). These individuals would be diagnosed as having MetS according to NCEP ATP III or AHA/ NHLBI criteria, but not by IDF criteria. Thus, MetS according to IDF criteria has lower prevalence. Under such condition, IDF definition will have less power, which may explain why IDF definition was less well correlated with cardiovascular risk factors in our study and previous work.

One of the limitations of our study is that it was cross-sectional and examined cardiovascular risk factors among MetS definitions. Although many studies have compared different definitions $[34,36,38,41-50]$, only one has compared more than four published definitions of MetS [36]. Instead of including the NCEP definition, Can's work examined the American College of Endocrinology (ACE) definition. In addition, microalbuminuria was not counted as a component in the WHO definition in their study. Although our study only provided cross-sectional relationships between MetS and cardiovascular risk factors, no cross-sectional study has compared five published definitions in relation to hs-CRP, arteriosclerosis, and PVD. Another limitation of our study is that insulin sensitivity was determined by HOMA-IR, and not the insulin sensitivity index derived from the hyperinsulinemic euglycemic clamp. Previous studies indicated that there existed a moderate to strong relationship between the HOMA-IR value and the insulin sensitivity index [51,52]. However, the insulin sensitivity index is not feasible for epidemiologic studies involving large numbers of participants. In addition, we did not perform oral glucose tolerance testing, so we may not provide valid estimate for the prevalence of MetS for the EGIR and WHO definitions by included some patients with T2DM or excluding some hyperglycemic cases that could be detected by glucose tolerance testing.

\section{Conclusions}

In conclusion, among the NCEP-ATP III, IDF, and AHA/ NHLBI definitions of MetS, the agreement among the definitions that do not require the measurement of insulin levels are from substantial to very good agreement, and the agreement between the WHO and EGIR definitions, the definitions that require the measurement of insulin sensitivity and fasting insulin levels, is substantial. Our data suggest that different definitions of MetS were correlated with all cardiovascular risk factors in women, but with different cardiovascular risk factors in men. In men, the modified NCEP ATP III and AHA/NHLBI (but not IDF) definitions were associated with an elevated level of hs-CRP and arterial stiffness independently of high-risk lifestyle behaviors, but the WHO definition seems to be more related to microalbuminuria and PVD. Since serum insulin, hs-CRP, baPWV, ABI, and urinary albumin are relatively costly measures compared with the other routine biologic markers, they are not feasible to be collected in everyday practice. Thus, our study findings provided new insight for diagnosis of MetS using various definitions in clinical practice.

\section{Abbreviations}

CVD: cardiovascular disease; HDL-C: high-density lipoprotein cholesterol; Mets: metabolic syndrome; WHO: World Health Organization; EGIR: European Group for the Study of Insulin Resistance; NCEP/ATP-III: National Cholesterol Education Program/Adult Treatment Panel III; AHA/NHLBI: American Heart Association and the National Heart, Lung and Blood Institute; IDF: International Diabetes Federation; hs-CRP: Highly sensitive Creactive protein; baPWV: brachial-ankle pulse wave velocity; ABI: ankle-brachial index; LDL-C: low-density lipoprotein cholesterol; HOMA-IR: insulin sensitivity was estimated with a Homeostasis Model Assessment; ACR: urinary albumin-to-creatinine ratio.

\section{Competing interests}

The authors declare that they have no competing interests.

\section{Authors' contributions}

CCL and TCL contributed equally to the design of the study and direction of its implementation, including supervision of the field activities, quality assurance and control. CSL, CIL, WYL, CCC, MML, TL, CYH, WC and PCC supervise the field activities. CSL and YDL helped conduct the literature review and prepare the Methods and the Discussion sections of the text. TCL, CSL, CCL, CHL, CWY and CIL designed the study's analytic strategy and conducted the data analysis. All authors read and approved the final manuscript.

\section{Additional material}

\section{Additional file 1}

Table S1. The relationships between cardiovascular risk factors and components of metabolic syndrome according to five definitions. Click here for file

[http://www.biomedcentral.com/content/supplementary/14712458-9-484-S1.DOC]

\section{Acknowledgements}

This study was supported by grants from the National Science Council of Taiwan (NSC93-23 |4-B-039-025\&NSC94-23 |4-B-039-024).

\section{References}

I. Isomaa B, Almgren P, Tuomi T, et al.: Cardiovascular morbidity and mortality associated with the metabolic syndrome. Diabetes Care 200I, 24:683-689.

2. Klein BE, Klein R, Lee KE: Components of the metabolic syndrome and risk of cardiovascular disease and diabetes in beaver dam. Diabetes Care 2002, 25:1790-I794.

3. Lakka HM, Laaksonen DE, Lakka TA, Niskanen LK, Kumpusalo E, Tuomilehto J, et al.: The metabolic syndrome and total and car- 
diovascular disease mortality in middle-aged men. JAMA 2002, 288:2709-27।6.

4. WHO: Definition, diagnosis and classification of diabetes mellitus and its complications: report of a WHO consultation. Geneva: World Health Organization; 1999.

5. Balkau B, Charles MA: Comment on the provisional report from the WHO consultation. European Group for the Study of Insulin Resistance (EGIR). Diabet Med 1999, I 6(5):442-443.

6. Adult Treatment Panel III: Executive summary of the third report of the National Cholesterol Education Program (NCEP) expert panel on detection, evaluation, and treatment of high blood cholesterol in adults (Adult Treatment Panel III). JAMA 200I, 285:2486-2497.

7. Alberti KG, Zimmet $P$, Shaw J: The metabolic syndrome--a new worldwide definition. Lancet 2005, 366(949I): I059-1062.

8. Grundy SM, Cleeman JI, Daniels SR, Donato KA, Eckel RH, Franklin BA, Gordon DJ, Krauss RM, Savage PJ, Smith SC Jr, et al:: Diagnosis and management of the metabolic syndrome: an American heart Association/National Heart, Lung, and Blood Institute Scientific Statement. Circulation 2005, I I 2( I7):2735-2752.

9. Yuyun MF, Adler Al, Wareham NJ: What is the evidence that microalbuminuria is a predictor of cardiovascular disease events? Curr Opin Nephrol Hypertens 2005, I 4:27I-6.

10. Tabeya T, Ohnishi H, Saitoh S, Akasaka H, Mitsumata K, Chiba M, Furugen M, Mori M, Shimamoto K: [Relationship of metabolic syndrome and insulin resistance with microalbuminuria in senior citizens of rural communities in Japan --the Tanno and Sobetsu study--]. Nippon Ronen Igakkai Zasshi - Japanese Journal of Geriatrics 2008, 45(3):302-307.

II. Hanai K, Babazono T, Iwamoto Y: Renal manifestations of metabolic syndrome in type 2 diabetes. Diabetes Research \& Clinical Practice 2008, 79(2):318-324.

12. Lin CC, Liu CS, Li TC, Chen CC, Li Cl, Lin WY: Microalbuminuria and the metabolic syndrome and its components in the Chinese population. European Journal of Clinical Investigation 2007, 37(10):783-790.

13. Choi HS, Ryu SH, Lee KB: The relationship of microalbuminuria with metabolic syndrome. Nephron 2006, 104(2):c85-93.

14. Blacher J, Asmar R, Djane S, London GM, Safar ME: Aortic pulse wave velocity as a marker of cardiovascular risk in hypertensive patients. Hypertension 1999, 33: IIII-IIII.

15. Saijo Y, Yoshioka E, Fukui T, Kawaharada M, Kishi R: Metabolic syndrome, C-reactive protein and increased arterial stiffness in Japanese subjects. Hypertension Research - Clinical \& Experimental 2006, 29(8):589-596.

16. Tsubakimoto A, Saito I, Mannami T, Naito Y, Nakamura S, Dohi Y, Yonemasu K: Impact of metabolic syndrome on brachial-ankle pulse wave velocity in Japanese. Hypertension Research - Clinical \& Experimental 2006, 29(I):29-37.

17. Miyaki K, Hara A, Naito M, Naito T, Nakayama T: Two new criteria of the metabolic syndrome: prevalence and the association with brachial-ankle pulse wave velocity in Japanese male workers. Journal of Occupational Health 2006, 48(2): 134-I 40

18. Nakanishi N, Shiraishi T, Wada M: Brachial-ankle pulse wave velocity and metabolic syndrome in a Japanese population: the Minoh study. Hypertension Research - Clinical \& Experimental 2005, 28(2):|25-13|.

19. Choi KM, Lee KW, Seo JA, Oh JH, Kim SG, Kim NH, Choi DS, Baik $\mathrm{SH}$ : Relationship between brachial-ankle pulse wave velocity and cardiovascular risk factors of the metabolic syndrome. Diabetes Research \& Clinical Practice 2004, 66(I):57-6I.

20. Lin WY, Lai MM, Li Cl, Lin CC, Li TC, Chen CC, Lin T, Liu CS: In addition to insulin resistance and obesity, brachial-ankle pulse wave velocity is strongly associated with metabolic syndrome in Chinese- A population-based study (Taichung Community Health Study, TCHS). Journal of Atherosclerosis and Thrombosis 2009, 16(2): 105-112.

21. Ridker PM, Rifai N, Rose L, Buring JE, Cook NR: Comparison of Creactive protein and low-density lipoprotein cholesterol levels in the prediction of first cardiovascular events. $N$ Engl Med 2002, 347: $1557-1565$.

22. Kuller LH, Tracy RP, Shaten J, Meilahn EN: Relation of C-reactive protein and coronary heart disease in the MRFIT nested case control study. Am J Epidemiol 1996, I 44:537-547.

23. Tong PC, Ho CS, Yeung VT, Ng MC, So WY, Ozaki R, Ko GT, Ma RC Poon E, Chan NN: Association of testosterone, insulin-like growth factor-I, and C-reactive protein with metabolic syndrome in Chinese middle-aged men with a family history of type 2 diabetes. Journal of Clinical Endocrinology \& Metabolism 2005, 90(I 2):64|8-6423.

24. Sung KC, Kim BJ, Kim BS, Lee WY, Park JB, Wilson AM: A comparison of the prevalence of the MS and its complications using three proposed definitions in Korean subjects. American Journal of Cardiology 2009, 1 03( I 2): 1732-1735.

25. Lin CC, Liu CS, Lai MM, Li Cl, Chen CC, Chang PC, Lin WY, Lee YD, Lin T, Li TC: Metabolic Syndrome and Its Associated Risk Factors in a Taiwanese Metropolitan Adult Population. BMC Public Health 2007, 7(I):739-743.

26. Lin WY, Liu CS, Li TC, Lin T, Chen Walter, Chen CC, Li Cl, Lin CC: In addition to insulin resistance and obesity, hyperuricemia is strongly associated with metabolic syndrome using different definitions in Chinese populations: a population-based study (Taichung Community Health Study). Ann Rheum Dis 2008, 67(3):432-433.

27. Pietrobelli A, Rubiano F, St Onge MP, Heymsfield SB: New bioimpedance analysis system: improved phenotyping with wholebody analysis. Eur J Clin Nutr 2004, 58: I479- I484.

28. Weitz JI, Byrne J, Clagett GP, et al.: Diagnosis and treatment of chronic arterial insufficiency of the lower extremities: a critical review. Circulation 1996, 94:3026-3049.

29. Matthews DR, Hosker JP, Rudenski AS, Naylor BA, Treacher DF, Turner RC: Homeostasis model assessment: insulin resistance and beta-cell function from fasting plasma glucose and insulin concentrations in man. Diabetologia 1985, 28(7):4|2-4|9.

30. Foundation NK: K/DOQI clinical practice guidelines for chronic kidney disease: evaluation, classification, and stratification. Am / Kidney Dis 2002, 39(2 Suppl I):SI-266.

3I. Wilson PW, D'Agostino RB, Levy D, Belanger AM, Silbershatz $H$, Kannel WB: Prediction of coronary heart disease using risk factor categories. Circulation 1998, 97:1837-1847.

32. Crepaldi Gaetano, Maggi Stefania: The metabolic syndrome: a historical context. Diabetes voice 2006, 5 I:8-I0.

33. Grundy SM, Cleeman JI, Daniels SR, et al.: Diagnosis and management of the metabolic syndrome: an American heart association/national heart, lung, and blood institute scientific statement. Circulation 2005, I I 2:2735-2752.

34. Dekker JM, Girman C, Rhodes T, Nijpels G, Stehouwer CD, Bouter LM, Heine RJ: Metabolic syndrome and I 0 -year cardiovascular disease risk in the Hoorn Study. Circulation 2005, I I 2(5):666-673.

35. Landis JR, Koch GG: The measurement of observer agreement for categorical data. Biometrics 1977, 33(I):159-174.

36. Can AS, Bersot TP: Analysis of agreement among definitions of metabolic syndrome in nondiabetic Turkish adults: a methodological study. BMC Public Health 2007, 7:353.

37. Guerrero-Romero F, Rodriguez-Moran M: Concordance Between the 2005 International Diabetes Federation Definition for Diagnosing Metabolic Syndrome With the National Cholesterol Education Program Adult Treatment Panel III and the World Health Organization Definitions. Diabetes Care 2005, 28:2588a-2589.

38. Choi KM, Kim SM, Kim YE, Choi DS, Baik SH, Lee J: Prevalence and cardiovascular disease risk of the metabolic syndrome using National Cholesterol Education Program and International Diabetes Federation definitions in the Korean population. Metabolism 2007, 56:552-558.

39. Jensen MD, Haymond MW, Rizza RA, Cryer PE, Miles JM: Influence of body fat distribution on free fatty acid metabolism in obesity. J Clin Invest 1989, 83(4): I I68-II

40. Khoo CM, Liew CF, Chew SK, Tai ES: The impact of central obesity as a prerequisite for the diagnosis of metabolic syndrome. Obesity (Silver Spring) 2007, 1 5:262-269.

4I. Lorenzo C, Williams K, Hunt KJ, Haffner SM: The National Cholesterol Education Program - Adult Treatment Panel III, International Diabetes Federation, and World Health Organization definitions of the metabolic syndrome as predictors of incident cardiovascular disease and diabetes. Diabetes Care 2007, 30:8-13.

42. Hanley AJ, Wagenknecht LE, D'Agostino RB Jr, Zinman B, Haffner SM: Identification of subjects with insulin resistance and beta-cell dysfunction using alternative definitions of the metabolic syndrome. Diabetes 2003, 52:2740-2747. 
43. Assmann G, Guerra R, Fox G, Cullen P, Schulte $H$, Willett $D$, Grundy SM: Harmonizing the definition of the metabolic syndrome: comparison of the criteria of the Adult Treatment Panel III and the International Diabetes Federation in United States American and European populations. Am J Cardiol 2007, 99:54I-548.

44. Ford ES: Prevalence of the metabolic syndrome defined by the International Diabetes Federation among adults in the U.S. Diabetes Care 2005, 28:2745-2749.

45. Cameron AJ, Magliano DJ, Zimmet PZ, Welborn T, Shaw JE: The metabolic syndrome in Australia: prevalence using four definitions. Diabetes Res Clin Pract 2007, 77:47I-478.

46. Sandhofer A, Iglseder B, Paulweber B, Ebenbichler CF, Patsch JR: Comparison of different definitions of the metabolic syndrome. Eur I Clin Inves 2007, 37:109-116.

47. Chen HJ, Pan WH: Probable blind spot in the International Diabetes Federation definition of metabolic syndrome. Obesity (Silver Spring) 2007, I 5:1096-II 00.

48. de Simone G, Devereux RB, Chinali M, Best LG, Lee ET, Galloway JM, Resnick HE: Prognostic impact of metabolic syndrome by different definitions in a population with high prevalence of obesity and diabetes: the Strong Heart Study. Diabetes Care 2007, 30: $185 \mid-1856$

49. Monami M, Marchionni N, Masotti G, Mannucci E: IDF and ATP-III definitions of metabolic syndrome in the prediction of allcause mortality in type 2 diabetic patients. Diabetes Obes Metab 2007, 9:350-353.

50. Nilsson PM, Engstrom G, Hedblad B: The metabolic syndrome and incidence of cardiovascular disease in non-diabetic subjects--a population-based study comparing three different definitions. Diabet Med 2007, 24:464-472.

51. Matsuda M, DeFronzo RA: Insulin sensitivity indices obtained from oral glucose tolerance testing: comparison with the euglycemic insulin clamp. Diabetes Care 1999, 22: | 462-I470.

52. Bonora E, Kiechl S, Willeit J, Oberhollenzer F, Egger G, Targher G, Alberiche M, Bonadonna RC, Muggeo M: Prevalence of insulin resistance in metabolic disorders: the Bruneck Study. Diabetes 1998, 47:1643-1649.

\section{Pre-publication history}

The pre-publication history for this paper can be accessed here:

http://www.biomedcentral.com/1471-2458/9/484/pre pub

Publish with Biomed Central and every scientist can read your work free of charge

"BioMed Central will be the most significant development for disseminating the results of biomedical research in our lifetime. "

Sir Paul Nurse, Cancer Research UK

Your research papers will be:

- available free of charge to the entire biomedical community

- peer reviewed and published immediately upon acceptance

- cited in PubMed and archived on PubMed Central

- yours - you keep the copyright 